\title{
Cirurgia parendodontica associada a terapia fotodinâmica: relato de caso com
}

\section{acompanhamento de 4 anos}

\author{
Paraendodontic surgery associate with photodynamic therapy: case report with 4 years follow-up \\ Cirurgia paraendodóntica asociada a terapia fotodinámica: reporte de um caso com seguimento de 4 \\ años
}

Recebido: 11/02/2021 | Revisado: 14/02/2021 | Aceito: 19/02/2021 | Publicado: 28/02/2021

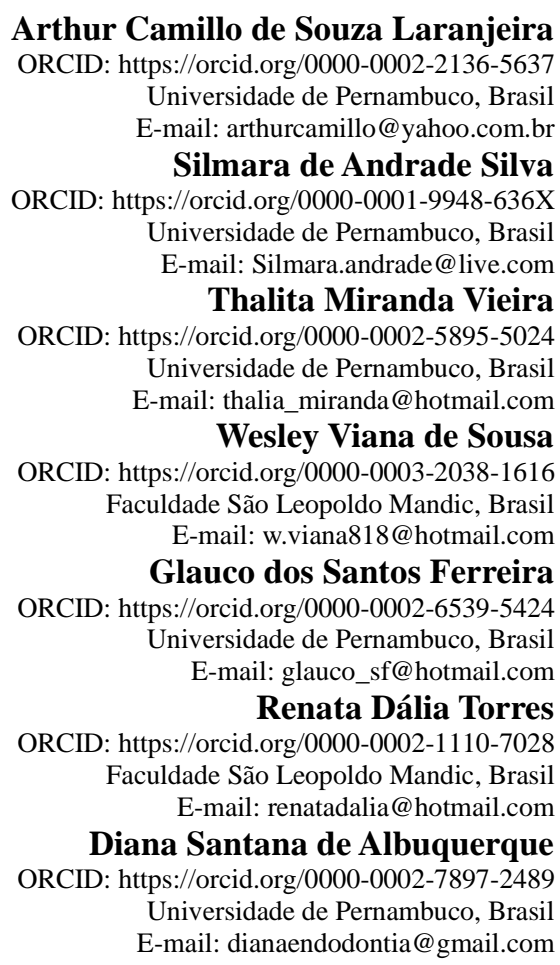

\begin{abstract}
Resumo
A cirurgia parendodôntica constitui um conjunto de procedimentos que têm como objetivo reparar complicações que não puderam ser solucionados através da endodontia convencional, ou quando essa não é passível de execução. Este estudo teve como objetivo descrever o caso clínico de uma cirurgia parendodôntica associada a terapia fotodinâmica no elemento dental 11. O caso foi conduzido realizando o acesso ao sistema de canais radiculares de forma retrograda. Foram realizadas: antissepsia intra/ extra bucal, anestesia infiltrativa, retalho para acesso, confecção da loja óssea, apicectomia, retroinstrumentação, terapia fotodinâmica, retrobturação, preenchimento da loja óssea, reposicionamento do retalho e sutura com acompanhamento tomográfico de feixe cônico de 4 anos. Concluímos que, a associação do ato cirúrgico com a aplicação de laser de baixa potência através da terapia fotodinâmica potencializou a desinfecção e a eliminação de bactérias persistentes ao fracasso do tratamento endodôntico anterior, propiciando benefícios adicionais ao paciente quando comparado à técnicas cirúrgicas convencionais.
\end{abstract}

Palavras-chave: Endodontia; Apicectomia; Obturação retrógrada.

\begin{abstract}
Parendodontic surgery is a set of procedures that aim to repair complications that could not be solved by conventional endodontics, or when it is not amenable to execution. This study aimed to describe the clinical case of a parendodontic surgery associated with photodynamic therapy on the upper right central incisor. The case was conducted with access to the root canal system in a retrograde way. Were performed: intra/extra buccal antisepsis, infiltrative anesthesia, surgical flap for access, the surgical cavity, apicectomy, retroinstrumentation, photodynamic therapy, retrofilling, filling the surgical cavity, flap repositioning, suture and a 4-year cone beam follow-up. We conclude that the association of the surgical procedure with the application of low-level laser through photodynamic therapy has
\end{abstract}


enhanced the disinfection and elimination of persistent bacteria to the failure of the previous endodontic treatment, providing additional benefits to the patient when compared to conventional surgical techniques.

Keywords: Endodontic; Apicoetomy; Retrograde obturation.

\section{Resumen}

La cirugía de Parendodoncia es un conjunto de procedimientos que tienen como objetivo reparar las complicaciones que no podrían resolverse con la endodoncia convencional, o cuando no son susceptibles de ejecución. Este estudio tuvo como objetivo describir el caso clínico de una cirugía parendodóntica asociada a la terapia fotodinámica en el elemento dental 11. El caso se realizó con acceso retrógrado al sistema de conductos radiculares. Se realizaron: antisepsia intra / extrabucal, anestesia infiltrativa, colgajo quirúrgico de acceso, confección de la cavidad quirúrgica, apicectomía, retroinstrumentación, terapia fotodinámica, retrofilling, llenado de la cavidad óseo, reposicionamiento del colgajo, sutura y monitorización tomográfica de haz cónico de 4 años. Concluimos que la asociación del acto quirúrgico con la aplicación de láser de baja potencia mediante terapia fotodinámica potenció la desinfección y eliminación de bacterias persistentes ante el fracaso del tratamiento endodóntico previo, proporcionando beneficios adicionales al paciente en comparación con las técnicas quirúrgicas convencionales.

Palabras clave: Endodoncia; Apicectomía; Obturación retrógrada.

\section{Introdução}

A permanência do dente na cavidade bucal se torna cada vez mais promissora na Odontologia. Entre as especialidades odontológicas responsáveis por esta longevidade dos dentes, a endodontia mostra-se com resultados favoráveis. Mesmo com grandes desafios para seu sucesso, procura-se obedecer ao rigor de etapas fundamentais, quais sejam: promover uma boa desinfecção, modelagem e selamento do sistema de canais radiculares (SCR), para que se consiga um bom prognóstico (Ribeiro, 2015). Entretanto, microrganismos podem resistir no interior do SCR, os quais radiograficamente, apresentam-se bem obturados.

Devido à variação anatômica do sistema de canais radiculares, tais microrganismos podem estar localizados em túbulos dentinários, áreas de achatamento, irregularidades anatômicas, deltas apicais, canais laterais e nas áreas de istmo, requerendo uma melhor desinfecção do SCR, através de protocolos de agitação da solução irrigadora e de recursos auxiliares da endodontia contemporânea (Lemos, 2009).

Mesmo dispondo artifícios e tecnologia para execução do tratamento e retratamento endodôntico convencional, estes ainda são passíveis de insucesso. Nos casos de insucesso dos retratamentos endodônticos não cirúrgico, faz-se necessário a intervenção endodôntica cirúrgica (Travassos et al., 2020). A cirúrgica parendodôntica que é praticada desde meados dos anos 1800, constituindo um conjunto de procedimentos que têm como objetivo reparar complicações que não puderam ser solucionados pela endodontia convencional, via coronal, ou quando esta não é passível de execução (Lopes, 2020; Lodi et al., 2008).

As indicações para cirurgias parendodonticas são em casos que o tratamento endodôntico convencional fracassou e/ou em casos de dificuldades de acesso ao canal radicular por via coronária, tais como: após a restauração com núcleo intracanal ou até mesmo como suporte de prótese fixa, em casos de lesões periapicais persistentes ou ainda com características císticas, canais radiculares calcificados com lesões periapicais, câmara pulpar com instrumentos fraturados, perfurações apicais e degraus, além de casos em que há extravasamento de material obturador (Torabinejah M, White S, 2016).

A cirurgia parendodôntica vem sendo mais previsível e simplificada quando se alia ao planejamento cirúrgico a tomografia computadorizada de feixe cônico (TCFC), A qual disponibiliza a visualização, de forma mais fiel, de medidas que servirão de referência durante o ato cirúrgico (Seedat et al., 2018). Além da TCFC, a Instrumentação Ultrassônica e a Terapia Fotodinâmica (PDT) também são recursos que associados ao procedimento cirúrgico promove maiores índices de eliminação de patógenos endodônticos (Trindade et al., 2017). 
Dessa forma, o objetivo desse estudo foi descrever o caso clínico de uma cirurgia parendodôntica por apicectomia associada à terapia fotodinâmica com instrumentação e obturação retrógrada, devido sobrextensão do material obturador no elemento 11 .

\section{Metodologia}

O presente artigo trata-se de um estudo de caso, de estrutura descritiva e qualitativa, onde é relatada a abordagem cirúrgica da cirurgia parendodôntica associada a terapia fotodinâmica. Quanto aos termos éticos, a paciente assinou o Termo de consentimento Livre e Esclarecido e foram respeitados os princípios éticos descritos na Declaração de Helsinque. (Pereira, et al., 2018)

\section{Relato de Caso Clínico}

Paciente D.S.L. 48 anos, sexo feminino, procurou o Centro de Pós-graduação em Odontologia (CPGO) em Recife no estado de Pernambuco por indicação de uma Cirurgiã-dentista (CD) após algumas tentativas frustradas de tratamento e retratamento endodôntico. Quanto aos termos éticos, a paciente assinou o Termo de consentimento Livre e Esclarecido.

A paciente relatou na anamnese que havia sido submetida a um tratamento restaurador do elemento 11 pois apresentava como queixa a sensibilidade ao tomar água gelada. O dente foi restaurado, porém a paciente ainda persistia com a mesma sintomatologia o que a fez voltar ao dentista que indicou o tratamento endodôntico a fim de sanar a dor presente.

Entre as sessões do tratamento endodôntico a paciente relatou que sentia dor, com isso, fazia uso de antibiótico e aguardou 15 dias para nova consulta. Mesmo após a medicação sistêmica, a paciente continuava a sentir dores, desta vez, espontânea e a obturação endodôntica foi realizada, relatou a paciente na anamnese.

Após a finalização do tratamento endodôntico a paciente relatou que as dores ainda persistiam e foi prescrito pelo CD, anti-inflamatório e analgésico a fim de reduzir os sintomas, porém, os sintomas ainda persistiam e a paciente alegou que sentia uma fístula na região e dor à mastigação.

Inconformada a paciente procurou mais três profissionais a fim de obter outras opiniões sobre o caso. Porém, apenas o quarto $\mathrm{CD}$, um ano após o primeiro tratamento, solicitou uma tomografia computadorizada à paciente e optou pelo retratamento endodôntico convencional, por ter visto uma sobrextensão do material obturador através do corte sagital.

Mesmo com o retratamento realizado a paciente continuava com a mesma sintomatologia, foi então que procurou outra profissional a qual, pelo histórico clínico, sugeriu que talvez fosse necessário realizar um procedimento cirúrgico, e encaminhou a paciente ao CPGO.

Ao chegar ao curso de especialização foram realizados os exames clínicos em que se observou a coloração normal da coroa clínica, sintomatologia dolorosa de sede localizada, com surgimento provocado (percussão vertical, horizontal, mastigação e palpação), de duração curta e intermitente. A paciente não apresentava edema, fístula e nem bolsa periodontal. Ao exame radiográfico foi observada uma leve alteração periapical.

Por fim, com base em todo o histórico e as informações colhidas chegou-se ao diagnostico de periodontite apical sintomática e o tratamento proposto foi a Cirurgia Parendodôntica. Para o planejamento cirúrgico, foi solicitado à paciente que ela realizasse os seguintes exames: Hemograma completo, coagulograma e glicose em jejum. Não foi necessária a solicitação da TCFC dado que a paciente já havia realizado recentemente. Todos os resultados estavam dentro dos padrões de normalidade, favorecendo a realização do procedimento cirúrgico. 
$\mathrm{Na}$ interpretação do corte coronal a obturação aparentava estar nos padrões da normalidade (Figura 1-A). Ao analisar as imagens nos cortes sagitais foi visto que havia sido extravasado, para a região perirradicular, 1,5 mm do cone principal de guta percha (Figura 1- B).

Figura 1 - Tomografia inicial. A: Corte coronal do dente 11. B: Corte sagital do elemento 11.

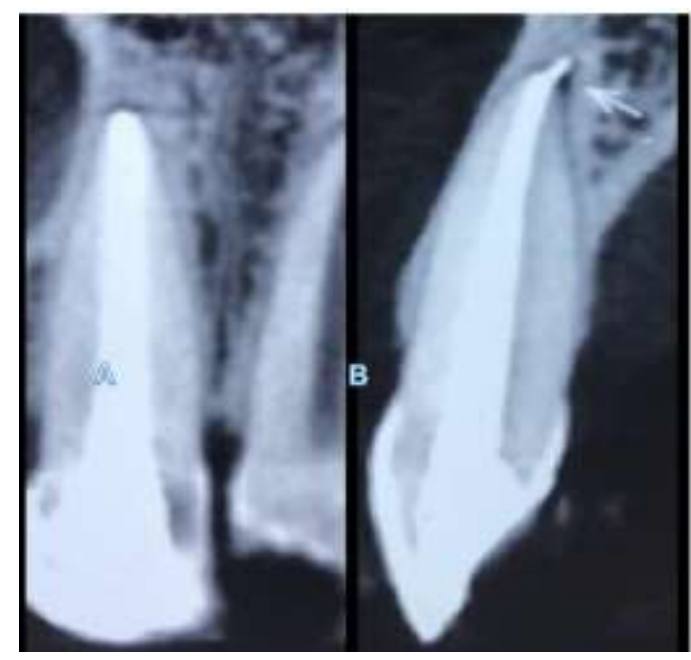

Fonte: Autores.

Como medicação pré-operatória foi prescrito a paciente $2 \mathrm{~g}$ de Amoxicilina, como dose profilática e $100 \mathrm{mg}$ de Nimesulida via oral (V.O) uma hora antes do procedimento cirúrgico, a fim de se evitar algum risco de infecção, inflamação e/ou desconforto proveniente da cirurgia.

A antissepsia extra bucal foi feita com digluconato de clorexidina $2 \%$ degermante, mantendo a cadeia asséptica, seguida pelo posicionamento do campo fenestrado estéril acima da paciente.

A anestesia do nervo alveolar superior anterior e infraorbital foi promovida com cloridrato de Mepivacaina a 2\% com epinefrina 1:100.00(DFL, Taquara, RJ, Brasil). Para a incisão foi utilizado bisturi $\mathrm{n}^{\circ} 15 \mathrm{C}$, fazendo uma incisão intrasucular que se estendeu da região do elemento 11 até o 24 , onde foi feita uma incisão relaxante. O descolamento subperiosteal foi feito com descolador de Molt.

Foi aferido o comprimento do dente na tomografia apresentada, onde tivemos uma medida de $25 \mathrm{~mm}$ para o elemento em questão. Com auxílio da sonda milimetrada PC15 a marcação para a realização do desgaste ósseo foi realizada em $26 \mathrm{~mm}$ devido a inclinação para palatina que o dente apresentava, tendo como referência a borda incisal do elemento. Com broca cirúrgica Carbide $n^{\circ} 04$ (FKG Sorense - São Paulo, Brasil) em alta rotação, sob irrigação copiosa de clorexidina 0,12\%, foi realizada a janela óssea (Figura 2) onde foi possível a visualização do cone de guta percha. 
Figura 2 - Janela óssea e exposição da porção apical radicular.

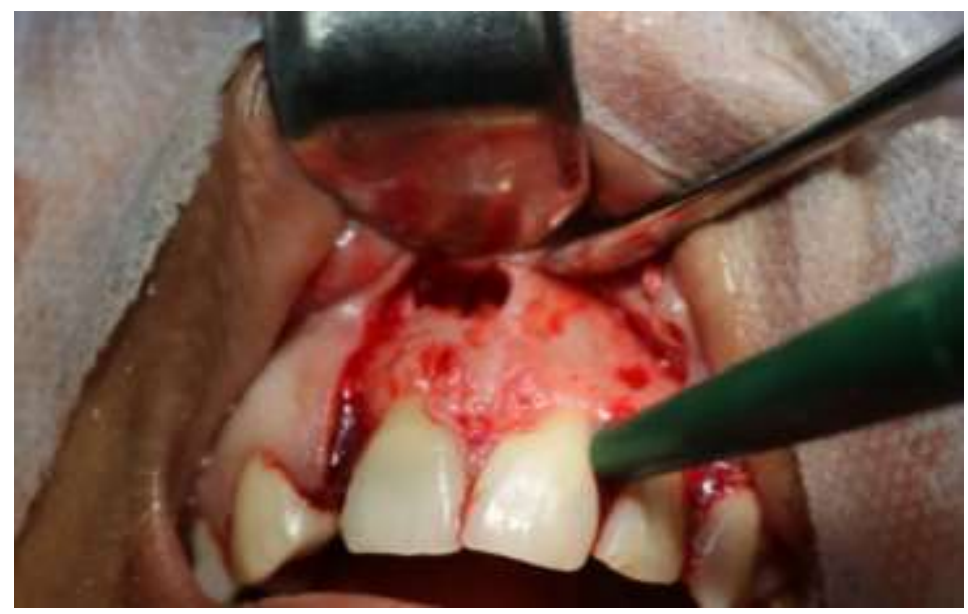

Fonte: Autores.

Para a apicectomia foi utilizada broca Zeckrya (Maillefer Denstsply - Suiça), removendo em $90^{\circ} 2 \mathrm{~mm}$ do ápice radicular. Em seguida foi realizado a instrumentação retrógrada com inserto de ultrassom P1 (Helse, Santa Rosa do Viterbo, Brasil), em $40 \%$ de potência, também sob irrigação de clorexidina a $0,12 \% \mathrm{em} 3 \mathrm{~mm}$ dentro do conduto. Ao término da retroinstrumentação o canal e a janela óssea foram inundados de Chimiolux 0,010\% (Azul de Metileno - Hypofarma, Belo Horizonte, Brasil), pré-irradiando por 5 minutos e foi aplicado o laser infravermelho em 5 aplicações de trinta segundos utilizando a configuração da Terapia Fotodinâmica (PDT) do aparelho Laser Duo da MMOptics emitido em 665nm e com potência de $30 \mathrm{~J} / \mathrm{cm}^{2}$. (Figura 3)

Figura 3 - Irradiação do laser infravermelho na loja óssea após apicectomia.

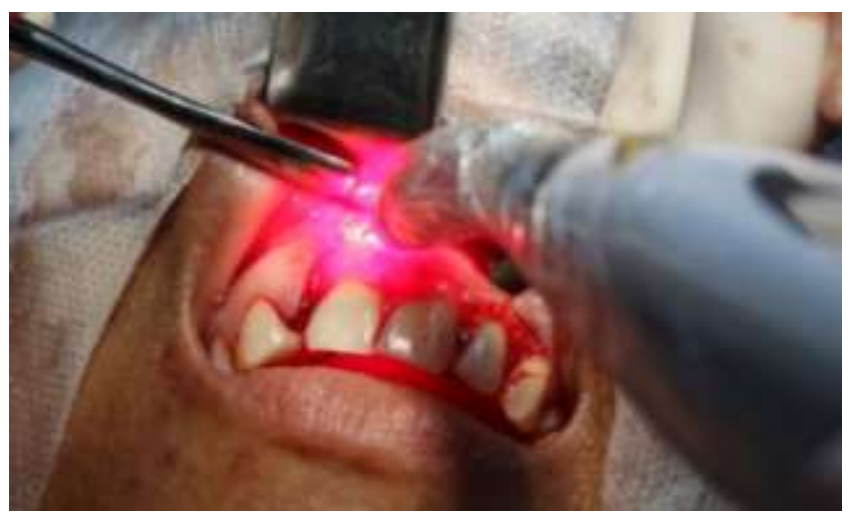

Fonte: Autores.

O fotossensibilizante foi removido pela irrigação com soro fisiológico e o dente foi retrobturado com Agregado De Trióxido Mineral (MTA) (Angelus, Londrina, Brasil). Para preencher a loja óssea o material escolhido foi o sulfato de cálcio hemi-hidratado (Lumina-set Criteria), que foi inserido na cavidade de forma gradativa (Figura 4- A). A finalização da cirurgia se deu por reposicionamento do retalho e sutura com fio Nylon 5.0. (Figura 4-B) 
Figura 4 - Preenchimento da loja óssea e sutura. A: Preenchimento da loja óssea com sulfato de cálcio. B: Reposicionamento do retalho e sutura.
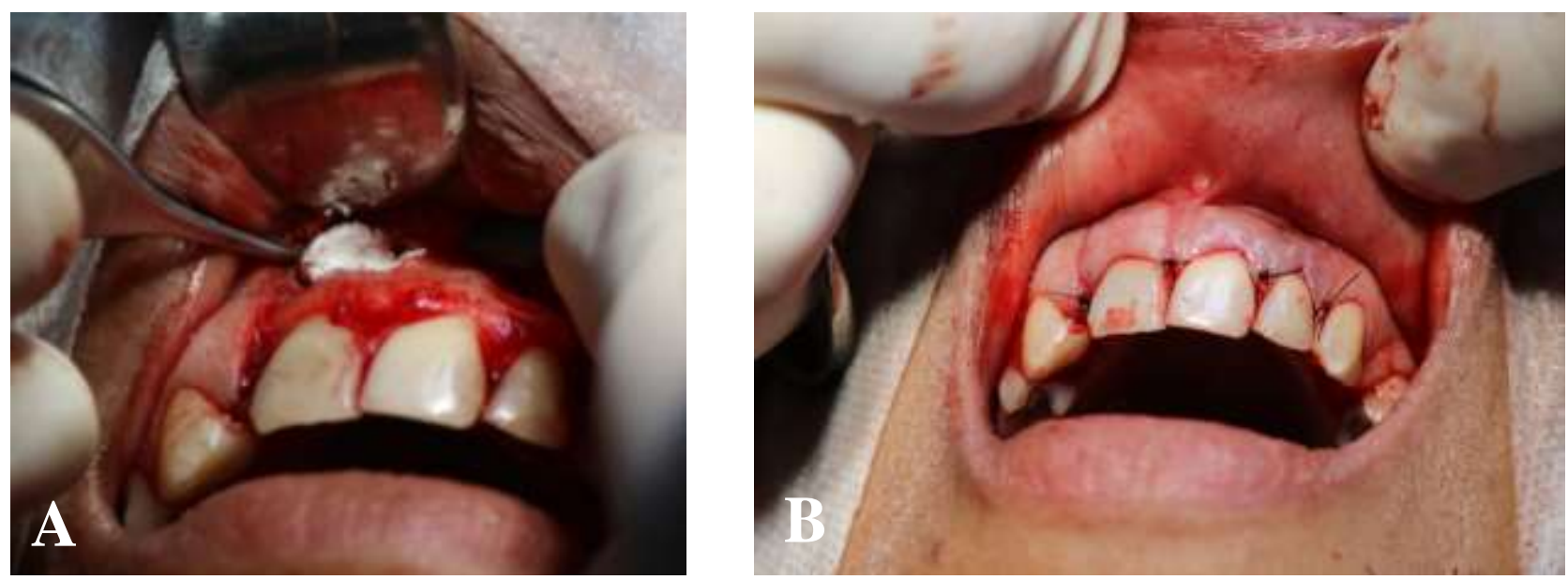

Fonte: Autores.

Foi prescrito para a paciente Amoxicilina de 500mg, 21 cápsulas, V.O., com a posologia de uma cápsula a cada 08 (oito) horas no período de 07 (sete) dias, bem como, antinflamatório esteroidal (Dexametasona 2mg) para evitar edema na região e analgésico não opióide, paracetamol 750mg, 01 comprimido, V.O. de 06/06 horas em caso de dor.

A paciente foi orientada em relação ao pós-cirúrgico, com todas as recomendações e cuidados por escrito em receituário.

No dia seguinte, a paciente apresentou um edema, mas livre de sintomatologia dolorosa. O edema regrediu dois dias após o seu surgimento. Assintomática e com a cicatrização dentro dos padrões de normalidade, a remoção da sutura foi feita 15 dias pós-cirurgia. A paciente foi acompanhada semestralmente e radiografias periapicais foram realizadas, para verificar a evolução do reparo. A tomografia de proservação foi realizada após 4 anos. (Figura 5)

Figura 5 - Corte tomográfico sagital, evidenciando a apicectomia realizada.

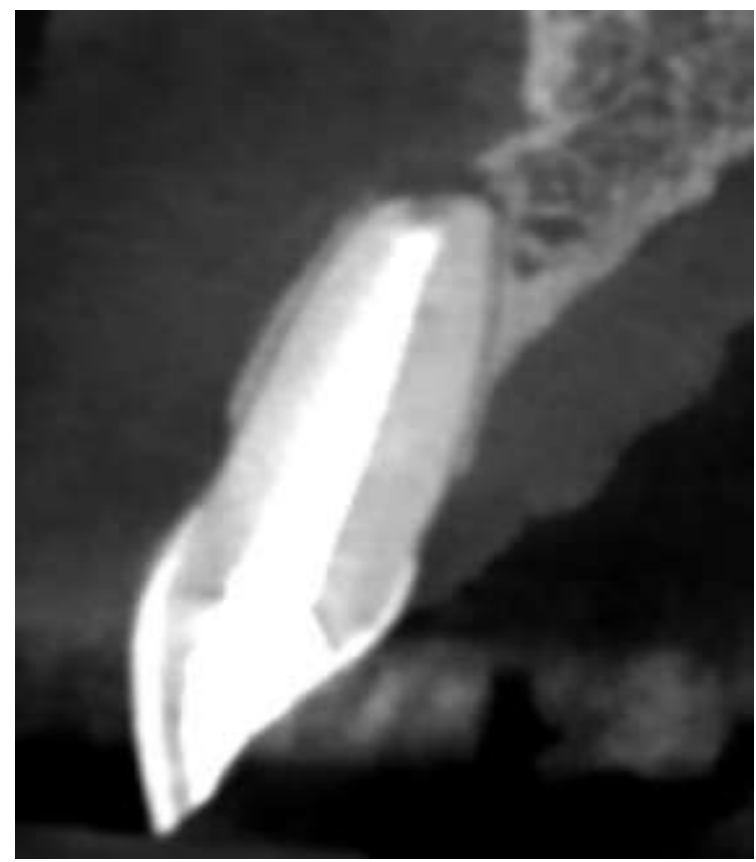

Fonte: Autores. 


\section{Discussão}

A cirurgia parendodôntica é uma opção de tratamento após o insucesso no tratamento convencional e/ou no retratamento ou quando algum destes não puderam ser realizados (Kohli, 2018; Sutter, 2020). Sendo assim, foi a opção de tratamento proposta a este caso visto que após tentativas frustradas de remoção do material obturador extravasado pelo acesso coronal persistia a sintomatologia dolorosa no elemento 11 relatada pela paciente.

Durante o tratamento endodôntico cirúrgico a cortical óssea necessita ser exposta para que seja possível alcançar a região onde será realizada a loja óssea (Baia et al., 2019). Existem diversos tipos de retalhos que podem ser realizados nessa cirurgia para obter acesso ao ápice radicular. Assim como foi visto nos relatos (Baia et al, 2019; Kastrev, 2019) o retalho triangular de Neumann oferece bom acesso e visualização do campo além de ser fácil de incisar, descolar (divulsionar) e de reposicionar e o paciente conseguir evoluir com boa higienização. Por esta razão foi a escolha neste caso onde foi realizada uma incisão sucular do dente 21 ao 14, junto a uma incisão relaxante obliqua na distal do 14 (Monteiro et al., 2018).

Nesta conduta foi realizada a apicectomia $90^{\circ}$ em relação ao longo eixo do dente, retirando $3 \mathrm{~mm}$ do ápice radicular. Os cortes apicais eram historicamente feitos em $30^{\circ}$ e $45^{\circ}$, entretanto com o advento da microscopia cirúrgica e insertos ultrassônicos este ângulo vem sendo reduzido para $90^{\circ}$ afim de facilitar a retroinstrumentação e a retrobturação (Xavier C B; Zambrano C B B, 2001).

A não associação da apicectomia à cirurgia parendodôntica seria negligenciar possíveis agentes causadores das lesões (Cunha, 2003). O objetivo da cirurgia apical é a remoção dos canais delta apical infectado junto a tecido patológico circundante e material obturador extravasado, quando presente, para garantir uma vedação hermética entre o canal radicular e o periodonto (Sutter et al., 2020).

Como escolha na retroinstrumentação modificada foi utilizado a instrumentação ultrassônica com o inserto P1 da Helse em $40 \%$ de potência, permitindo a confecção de cavidade retrógrada com três milímetros de profundidade e sob irrigação copiosa com Digluconato de Clorexidina à $0,12 \%$ afim de promover uma melhor desinfecção no momento da instrumentação (Seedat et al., 2018; Kohli et al., 2018; Deleme; Aldabagh, 2020; Zandi et al., 2019). Dentre as inúmeras vantagens da utilização do ultrassom nas cirurgias parendodônticas, podemos relatar que mesmo diante de dificuldades anatômicas, é possível, na maior parte dos casos, inserir as pontas ultrassônicas paralelas em relação ao longo eixo do canal radicular tornando os preparos mais paralelos, permitindo menor desgaste das paredes dentinárias, resultando em preparos mais conservadores e com paredes mais volumosas ou espessas. Além do que na confecção das cavidades apicais realizadas com ultrassom consegue-se um preparo mais profundo do que quando se utilizam brocas convencionais (Gilbert et al., 2010; Berstein et al., 2012; Seedat et al., 2018).

Em seguida, como medida para aumentar a eficácia da desinfecção foi empregado o azul de metileno 0,010\% (Chimiolux) preenchendo toda a janela óssea e associando ao laser infravermelho de baixa potência, atuando assim como terapia fotodinâmica gerando a liberação de radicais livres que proporcionam efeito bactericida (Souza et al., 2019). A utilização do laser de baixa frequência é segura, de fácil manipulação e aceitação pelo paciente, técnica seletiva além de promover atividade antimicrobiana quando associado a um corante fotossensibilizador, não causa efeitos sistêmicos e não promove resistência bacteriana (Trindade et al., 2017; Souza et al., 2019; Vieira et al., 2018; Masuda et al., 2018). Após análise molecular sobre o efeito antimicrobiano da PDT que quando esta terapia é usada junto às cirurgias endodônticas, o nível de bactérias e estreptococos, presente na cavidade radicular e na superfície de corte, diminuiu significativamente. Na pesquisa, também evidencia que os casos tratados com PDT exibiram uma alta taxa de cicatrização (Vieira et al., 2018).

A escolha do material para a retrobturação se deu pelo fato de o material apresentar biocompatibilidade, realizar um selamento hermético na região apical, radiopacidade e baixa toxicidade. Além disso, pesquisas evidenciam que o MTA pode induzir reparo nos tecidos da região periapical e que apresenta alta capacidade seladora além de propriedades mecânicas 
caracterizando-se como um bom material selador apical, mesmo com contato do sangue ou umidade. Sobretudo, as obturações com MTA fornecem ao dente maior resistência à fratura (Tang et al., 2019; Safi et al., 2019).

Por apresentar inúmeras vantagens, além de ser uma alternativa viável e segura, tanto como material de enxerto como material de preenchimento, o sulfato de cálcio tem sido bastante usado como material de preenchimento aglutinante e enxerto ósseo. Possui muitas características de um material ideal para a regeneração óssea. Ele fornece um cimento eficaz para o aumento maxilofacial, é fácil de usar e econômico, além de que não requer cobertura completa de tecidos moles ou uma membrana (Yahav et al., 2020).

Entretanto nenhuma cirurgia paraendodôntica resultará em sucesso se o canal não estiver bem obturado ou se não for possível, por meio da cirurgia, melhorar suas condições de selamento. Portanto, antes de optar pela realização de uma cirurgia, todas as tentativas de tratamento convencionais devem ser feitas, com o objetivo de solucionar o problema por via câmara pulpar (Torabinejah et al., 2016; Seedat et al., 2018; Werlang et al., 2016).

\section{Considerações Finais}

A associação do ato cirúrgico com a aplicação de laser de baixa potência através da terapia fotodinâmica potencializou a desinfecção e a eliminação de bactérias persistentes ao fracasso do tratamento endodôntico anterior, propiciando melhor prognóstico e benefícios adicionais ao paciente quando comparado à técnicas cirúrgicas convencionais diminuído o índice de insucessos. O desenvolvimento de protocolos associando o laser de baixa potência na endodontia pode facilitar o sucesso durante os tratamentos endodônticos. No entanto, mais estudos in vivo são necessários para avaliar a relevância clínica.

\section{Referências}

Baia, D., Marques, A., Sponchiado-Júnior, E., Garcia, L., Pandolfo, M. Bortoluzzi, E., \& De Carvalho, F. (2019). Endodontic surgery associated with guided tissue regeneration technique: Case report. Journal of Health Sciences, 21(4), 336-41, https://doi.org/10.17921/2447-8938.2019v21n4p336-41

Bernstein, S., Horowitz, A., Man, M., Wu, H., Foran, D., Vena, D., Collie, D., Matthews, A., Curro, F., Thompson, V., \& Criag, R. (2012) Outcomes of endodontic therapy in general practice: A study by the practitioners engaged in applied research and learning network. JADA. 143(5):478-487. 10.14219/jada.archive.2012.0208

Cunha, F., \& Júlio, J. (2003). Estudo Comparativo in vitro da morfologia das raízes dentárias submetidas a apicectomia com fresas cirúrgicas e diferentes tipos de lasers. Doctoral thesis.

Deleme, Z., \& Aldabagh, A. (2020). The effects of bio adhesive chlorhexidine gel, nsaids on post-operative sequelae after periapical surgery of upper anterior teeth. International Journal, 8.1: 27-30. 10.12691/ijdsr-8-1-5

Gilbert, G., Tilashalski, K., Litaker, M., McNeal, S., Boykin, M., \& Kessler, A. (2010). Outcomes of root canal treatment in dental practice-based research network practices. Gen Dent. 58(1): 28-36. https://pubmed.ncbi.nlm.nih.gov/20129890/

Jr., W., Rodrigues, R., \& Silva, T. (2006). Sulfato de cálcio como barreira e material de preenchimento associado ao osso autógeno no tratamento de defeito ósseo periodontal- Proposta de tratamento e relato clínico. Innovations dental jornal. https://silo.tips/download/wilson-trevisan-jr-marcia-regina-rodriguesthiago-bezerra-da-silva-e-janice-de-c

Kohli, M., Berenji, H., Setzer, F., Lee, S., \& Karabucak, B. (2018). Outcome of endodontic surgery: A meta-analysis of the literature- Part 3: Comparision of endodontic microsurgical techniques with 2 different root-end filling materials. Journal of Endodontics. 44(6), 923-931. 10.1016/j.joen.2018.02.021

Kastrev, B., \& Filipov, I. (2019). Periapical surgery. Review. Classic VS modern concepts. International Journal of Medical Reviews and Case Reports. 3(12). 10.5455/IJMRCR.periapical-surgery

Lemos, S. (2009) Cirurgia Parendodontica: Como realizá-la com embasamento científico-Técnicas e materiais. Course conclusion work. http://www.iesposgraduacao.com.br/assets/downloads/40ac0651a7b1fd2dd072f3bb0595c498.pdf

Lodi, L., Poleto, S., Soares, R., Irala, L., Salles, A., \& Limongi, O. (2008). Cirurgia parendodôntica: relato de caso clínico. RSBO. 2(5). http://univille.edu.br/community/depto_odontologia/VirtualDisk.html?action=downloadFile\&file=11_Cirurgia\%20paraendodontica\%20relato\%20de\%20caso \%20clinico.pdf\&current=\%2FODONTOLOGIA\%2FRSBO\%2FRSBO_v5_n2_agosto2008

Lopes, H., \& Siqueira, Jr. (2020). Endodontia: Biologia e técnica. (5a ed.). Guanabara Koogan.

Masuda, Y., Sakagami, H., Horike, M., Kadokura, H., Yamasaki, T., Klokkevold, P., \& Yokose, S. (2018). Photodynamic therapy with pyoktanin blue and 
diode laser for elimination of enterococcus faecalis. In Vivo. 10.21873/invivo.11298

Monteiro, J., Dal Piva, A., Tribst, J., Borges, A., \& Tango, R. (2018). The effect of resection angle on stress distribution after root-end surgery. Iranian Endodontic Journal. 13(2), 188. 10.22037/iej.v13i2.19089

Pereira A. S. et al. (2018). Metodologia da pesquisa científica. UFSM. https://repositorio.ufsm.br/bits tream/handle/1/15824/Lic_Computacao_MetodologiaPesquisa-Cientifica.pdf?sequence $=1$

Prati, C., Pirani, C., Zamparini, F., Gatto, M., \& Gandolf, M. (2018). A 20-years historical prospecrive cohort study of root canal treatments. A multilevel analysis. International Endodontic Journal. 51(9), 955-968. 10.1111/iej.12908

Ribeiro, M. (2015). Estudo clínico do conteúdo inflamatório e infeccioso de dentes com insucesso do tratamento endodôntico. Doctoral thesis.

Safi, C. (2019). Outcome of endodontic microsurgery using mineral trioxide aggregate or Root repair material as root-endo filling material: a randomized controlled trial with cone-bean computed tomographic evaluation. Journal of Endodontics. 45(7). 10.1016/j.joen.2019.03.014

Seedat, H., Van Der Vyver, P., \& De Wet, F. (2018). Micro-endodontic surgery part 1: Surgical rationale and modern techniques. South African Dental Journal. www.scielo.org.za/scielo.php?script=sci_arttext\&pid=S0011-85162018000300007\&lng=en\&nrm=iso

Seedat, H., Van Der Vyver, P., \& De Wet, F. (2018). Micro-endodontic surgery part 2: Root-end filling materials- A literature review. South African Dental Journal. 73(5), 336-342. http://dx.doi.org/10.17159/2519-0105/2018/v73no5a2

Souza, M., Rauber, M., Zuchi, N., Bonacina, L., Ricci, R., Dias, C., Bischoff, K., Engelmann, J., \& Palhano, H. (2019). Influence of final irrigation protocols and endodontic sealer on bond strength of root filling material with root dentin previously treated with photodynamic therapy. Photodiagnosis and Photodynamic Therapy. 10.1016/j.pdpdt.2019.03.013

Sutter, E., Valdec, S., Bichsel, D., Wiedemeier, D., Rucker, M., \& Stadlinger. B. (2020). Success rate 1 year after apical surgery: A retrospective analysis. Oral and Maxillofacial surgery. 24(1), 45-49. 10.1007/s10006-019-00815-9

Tang, J., Shen, Z., Qin, W., \& Lin, Z. (2019) A comparision of the sealing abilities btween biodentine and MTA as root-end filling materials and their effects on bone healing in dogs after periradicular surgery. Journal of Applied Oral Science. https://doi.org/10.1590/1678-7757-2018-0693

Torabinejad, M., \& White, S. (2016). Endodontic treatment options after unsuccessful initial root canal treatment: Alternatives to single tooth implantes. The Journal of The American Dental Association. 147(3). 10.1016/j.adaj.2015.11.017

Travassos, R., Negreiros, J., Farias, W., Soares, T., Barbosa, L., Souza, T., \& Silva, H. (2020). Apicectomia e obturação retrógrada de dente com calcificação radicular interna: Relato de caso. Research, Society and Development. 9(9). e327997390, http://dx.doi.org/10.33448/rsd-v9i9.7390

Trindade, A., De Figueiredo, J., De Oliveira, S., Barth Juinor, V., Gallo, S., Follmann, C., \& Weber, J. (2017). Histopathological, microbiological and radiographic analysis of antimicrobial photodynamic therapy for the treatment of teeth with apical periodontitis: A study in rats'molars. Photomedicine and Laser Surgery. 35(7), 364-371. 10.1089/pho.2016.4102

Vieira, G., Antunes, H., Pérez, A., Gonçalves, L., Antunes, F., Siqueira Jr, J., \& Rôças, I. (2018). Molecular analysis of the antibacterial effects of photodynamic therapy in endodontic surgery: A case report. Journal of Endodontics. 44(10), 1593-1597. 10.1016/j.joen.2018.06.012

Werlang, A., Baldissarelli, F., Werlang, F., Vanni, J., \& Hartmann, M. (2016). Insucesso no tratamento endodontico: uma revisão de literatura. Revista Tecnológica. 5(2), 31-47. https://uceff.edu.br/revista/index.php/revista/article/view/146/137

Xavier, C., \& Zambrano, C. (2001) Avaliação da ressecção apical e indicação de materiais obturadores em cirurgias parendodôntica no Brasil. Estudo de Campo. https://pesquisa.bvsalud.org/portal/resource/pt/lil-313008

Yahav, A., Kurtzman, G., Katzap, M., Dudek, D., \& Baranes, D. (2020). Bone regeneration: properties and clinical application of biphasic calcium sulfate. Dental clinics. 64(2):453-472. 10.1016/j.cden.2019.12.006.

Zandi, H., Petronijevic, N., Mdala, I., Kristoffersen, A., Enersen, M., Rôças, I., Siqueira Jr, J., \& Orstavik, D. (2019). Outcome of endodontic retreatment using 2 root canal irrigants and influence of injefction on healing as determined by a molecular method: A randomized Clinical Trial. Journal of endodontics. 45.9: 1089-1098. 10.1016/j.joen.2019.05.021 